\title{
A PILOT STUDY FOR EVALUATION OF ROLE OF B-MODE ULTRASOUND AND STRAIN ELASTOGRAPHY IN DIFFERENTIATING BENIGN AND MALIGNANT BREAST MASSES
}

\author{
SARYU GUPTA ${ }^{1}$, MANPREET KAUR ${ }^{1}$, AMARJIT KAUR ${ }^{1}$, KULDEEP BHATIA $^{2}$
}

${ }^{1}$ Department of Radiodiagnosis, Government Medical College and Rajindra Hospital, Patiala, Punjab, India. ${ }^{2}$ Department of Surgery, Government Medical College and Rajindra Hospital, Patiala, Punjab, India. Email: drsaryugupta@gmail.com

Received: 15 May 2021, Revised and Accepted: 20 June 2021

\section{ABSTRACT}

Background: Early detection of malignant lesions is critical key stone for the successful management of breast cancer. Conventional B-mode ultrasound although could not replace the histopathology which is still gold standard, plays an important role in the diagnostic pathways by using the Breast Imaging Reporting and Data System (BIRADS) lexicon (standardized by American College of Radiology [ACR]). Although characterization of solid breast masses by sonography has improved greatly since the early 1990s, specificity remains low and a large number of biopsies result in benign diagnosis. Strain elastography and strain ratio (SR) are recent techniques which may help in increasing the specificity of ultrasound.

Methods: The present study was a pilot study aimed to establish a correlation between B-mode ultrasound and strain elastography in differentiating benign and malignant breast masses and to compare the results of B- mode ultrasound and Strain Elastography with fine-needle aspiration cytology/ biopsy findings. It was a prospective study conducted in the Department of Radio-diagnosis of Rajindra Hospital, Patiala. A total of 40 patients who presented with the complaint of palpable breast lump were evaluated with B-Mode Ultrasonography (USG) and Strain elastography (using elastography score [ES] and SR).

Results: The study group (40 patients with breast lumps) comprised 38 (95\%) female patients and 2 (5\%) male patients. Among the group 29 were benign and 11 were malignant. Fibroadenoma followed by fibrocystic disease was the most common benign pathologies and invasive ductal carcinoma followed by Ductal Carcinoma in situ was the most common malignant pathologies. Sensitivity, specificity, and diagnostic accuracy of B-Mode USG in diagnosing palpable breast lump are 72.7\%, 86.2\%, and $82.5 \%$, respectively, while that of strain elastography in diagnosing palpable breast lump are $81.8 \%, 93.10 \%$, and $90.0 \%$, respectively. Using strain ratio (SR) only the sensitivity, specificity, and diagnostic accuracy was found to be $93.1 \%, 100 \%$, and $95 \%$ better than B-Mode USG and shear elastography alone separately and combined. The mean SR for a benign mass is $2.00 \pm 0.97$ and for a malignant mass is $5.40 \pm 1.55$.

Conclusion: Ultrasound elastography (using ES) has a higher sensitivity, specificity and diagnostic accuracy in differentiating benign and malignant breast masses then B mode USG (using BIRADS). Using SR alone has shown better sensitivity, specificity, and diagnostic accuracy but its standalone or in combination diagnostic application has to be followed up with further studies.

Keywords: Breast lump, Elastography, Strain ratio, Breast imaging reporting and data system.

(c) 2021 The Authors. Published by Innovare Academic Sciences Pvt Ltd. This is an open access article under the CC BY license (http://creativecommons.org/ licenses/by/4.0/) DOI: http://dx.doi.org/10.22159/ajpcr.2021v14i7.42378. Journal homepage: https://innovareacademics.in/journals/index.php/ajpcr

\section{INTRODUCTION}

Palpable breast mass is one of the common complaints of all ages particularly during the reproductive age. Palpable breast masses are usually benign however efficient evaluation along with prompt diagnosis is necessary to rule out malignancy [1]. Breast cancer is the most common type of cancer among women worldwide, affecting 2.1 million women each year. It is the leading cause of cancer related deaths among females today with around $15 \%$ of cancer related deaths among women. In India also breast cancer is the most common cancer among women accounting for $14 \%$ of all cancers. According to GLOBACAN 2020; 178361 new cases of breast cancer were registered and 90,408 deaths were registered due to breast cancer [2].

Benign breast masses include cysts, fibroadenoma, fibro adenosis, fibro-adenomatous hyperplasia, intra-ductal papilloma, inflammation, lipomas, and benign phyllodes tumor [3].

Malignant breast masses include invasive ductal carcinoma (IDC), ductal carcinoma in situ (DCIS), intra-ductal papillary carcinoma, and mucinous carcinoma.

Several studies have described the sonographic characteristics commonly seen in benign lesions of the breast $[4,5]$.
- Smooth and well circumscribed

- Thin echogenic capsule

- Hyperechoic, isoechoic, or mildly hypoechoic

- Ellipsoid shape, with the transverse diameter more than anteroposterior diameter

- Three or fewer gentle lobulations

- Absence of any malignant findings.

Malignant lesions are usually hypoechoic lesions with ill-defined borders. Typically, a malignant lesion presents as a hypoechoic lesion, which is "taller than broader" and has spiculated margins, posterior acoustic shadowing and microcalcifications [4]. Color Doppler has not proven to be very efficacious in improving the specificity of ultrasonography (USG); however, in certain situations it may help to resolve the issue, particularly when there is significant vascularity present within highly cellular types of malignancies [6].

The downside of USG is an increased false positive rate and lower positive predictive value (PPV). To obtain an acceptable specificity various eight characteristics of the lesion must be evaluated according to the breast imaging reporting and data system (BIRADS) criteria defined by American College of Radiology (ACR). However, BIRADS criteria generate significant number of false positive results [7]. 
Ultrasound elastography aims to overcome the limitations of ultrasound and to obtain an accurate characterization of breast lesions. It depicts the stiffness of tissues [8]. Elastography techniques are of two types; first is dynamic elastography which included shear wave and acoustic radiation force pulse while the second is static elastography which includes strain elastography [8].

Strain elastography allows evaluation of the elasticity score (ES) as a qualitative parameter of stiffness and the strain ratio (SR) as a semiquantitative method for numerically evaluating how many times stiffer a target mass is compared to the subcutaneous fat [9].

The elastography score (ES) will be interpreted according to the 5-point TSUKUBA Scoring method proposed by Itoh et al. in 2006 [8].

A score of 1-3 indicates toward a probably benign mass while a score of 4 and 5 should raise a suspicious of malignancy. This system is said to have a sensitivity of $87 \%$, specificity of $90 \%$, and diagnostic accuracy of $88 \%$.

SR is defined as the fat to mass SR and will be automatically calculated by the embedded software program in the ultrasound unit. The higher the strain-ratio the higher the likelihood of malignancy.

$\mathrm{SR}=$ Mean strain of fat area/mean strain in lesion of interest [10].

Although characterization of solid breast masses by sonography has improved greatly since the early 1990s, specificity remains low and a large number of biopsies ( $>50 \%$ ) result in benign diagnosis. Strain elastography is a recent technique which may help in increasing the specificity of ultrasound and hence reducing the biopsy load. The study aimed at assessing the diagnostic role of strain elastography and its parameters.

\section{Aims and Objectives}

The objectives are as follows:

1. Assess the diagnostic role of strain elastography and SR

2. Compare the results of B-mode ultrasound and strain elastography with fine-needle aspiration cytology (FNAC)/biopsy findings.

\section{METHODS}

This prospective observational analytic pilot study was carried out in the Department of Radio-Diagnosis, Rajindra Hospital, Patiala. The study included 40 consenting patients of 18 years and above among the ones presenting with breast lump in the outpatient department or admitted in the wards in Rajindra Hospital, Patiala, who were referred to the Department of Radiodiagnosis for investigation and were after enrollment were latter followed up to histopathology of the lump. The patients who are below 18 years, already diagnosed and treated for breast lump, or had physiological or post-traumatic or post-infective breast swelling and who did not give consent were excluded from the study.

Sample size was calculated using formula $\left(\mathrm{Z}_{1-/ 2}{ }^{\alpha} \mathrm{p}(1-\mathrm{p})\right) / \mathrm{d}^{2}$ where $\mathrm{Z}_{1-/ 2}{ }^{\alpha}$ is Standard normal variate $1.96, \mathrm{~d}$ is absolute error which is taken $10 \%$ in this study and $\mathrm{p}$ is expected proportion in population which in this study is expected population getting histopathology out of population who have lump in breast which was taken as $10 \%$ based on previous records who fulfill the inclusion criteria. The calculated sample size was 35 and keeping $10 \%$ as expected loss during study and follow-up the sample size was rounded up to 40 patients.

\section{Instrumentation, Patient Positioning, and Breast Survey Techniques}

B-Mode ultrasound and Strain Elastography were performed using PHILIPS EPIQ5 S.NO. U5318C0517 machine using high frequency L125 transducer. Each lesion was assessed with the BIRADS).

Sonographic parameters including size, shape, margin, orientation, posterior acoustic features, calcifications, axillary lymphadenopathy, and internal vascularity. The BIRADS categories were assigned according to the BIRADS US lexicon, $5^{\text {th }}$ edition, by the ACR in 2013 .

\begin{tabular}{ll}
\hline BIRADS staging & Interpretation \\
\hline BIRADS 1 & Normal \\
BIRADS 2 & Definitely benign \\
BIRADS 3 & Probably benign \\
BIRADS 4 & Probably malignant \\
BIRADS 5 & Definitely malignant \\
BIRADS 6 & Known malignancy \\
\hline BIRADS: Breast
\end{tabular}

Doppler characteristics such as absence of flow, distribution, and pattern of vessels in the mass lesion were also noted. The location of the lesion was labeled according to o'clock position and distance from the nipple. The anterior, posterior, and lateral dimensions were recorded for the reference of $\mathrm{AP} / \mathrm{L}$ ratio.

Then using the same probe, strain elastography was performed while keeping the probe perpendicular to the skin during compression. The region of interest (ROI) was set for elastography acquisition; superior margin includes subcutaneous fat; inferior margin include pectoral muscle; and lateral margin should have $10 \mathrm{~mm}$ distance from the lesion. The target lesion was compressed vertically by applying light pressure. High levels of pressure were avoided because in such cases the association between pressure and strain is no longer proportional and false results may be found.

The ES and SR were measured on coupled B-Mode and Elastography images. Inside the field of view box, we positioned the first ROI in the lateral subcutaneous fat tissue at the same depth as the target lesion and with the second ROI we outlined the entire lesion.

The ES was interpreted according to the 5-point TSUKUBA Scoring method proposed by Itoh et al. in 2006 [8] [Figure 1]

\section{TSUKUBA scoring system [8]}

Score 1 - even strain for entire hypo-echoic lesion (i.e. the entire lesion is evenly shaded in blue).

Score 2 - strain in most of the hypo-echoic lesion (i.e. the hypo-echoic lesion has the mosaic pattern of blue and green).

Score 3 - strain at the periphery of the hypo-echoic lesion (i.e. peripheral part is blue and the central part is red)

Score 4 - no strain in the entire hypo-echoic lesion (i.e. the entire lesion is red but the surrounding area is not included).

Score 5 - no strain in the entire hypo-echoic lesion or in the surrounding area (i.e. both the entire lesion and its surrounding area are red).

A ES of 1 to 3 indicates toward a probably Benign mass while a score of 4 and 5 should raise a suspicious of malignancy.

\section{Data collection and analysis}

Data collection and analysis was done using Microsoft Excel, Epi info version 7.2.4.0 (CDC Atlanta) and Medcalc Statistical Software version [12]. Most of the values are described in percentages and means, while other analytic tests included Shapiro-Wilk Test (For normality of data, Chisquare test, Fisher's Exact, Mann-Whitney test, ROC analysis, and Kendell Rank correlation coefficient test. Diagnostic utility parameters such as sensitivity, specificity, Youden index ( $50 \%$ benchmark for diagnostic utility), PPV, negative predictive value (NPV), and Kappa were also calculated.

\section{RESULTS}

The final pathological diagnosis showed the benign masses to be 72.5 $\%$ (29 cases) and malignant breast lumps to be $37.5 \%$ (11 patients) of 
Table 1: Distribution of study population according to the age

\begin{tabular}{|c|c|c|c|c|c|c|c|c|c|c|}
\hline \multicolumn{11}{|l|}{ (a) Mean } \\
\hline Age & Obs & Mean & Std Dev & Min & $25 \%$ & Median & $75 \%$ & Max & Mode & p-value \\
\hline Study population & 40 & 37.28 & 13.21 & 20 & 28 & 32 & 49.5 & 70 & 30 & \\
\hline Malignant & 11 & 51.64 & 11.91 & 33 & 38 & 52 & 60 & 70 & 60 & \\
\hline \multicolumn{11}{|c|}{ *Mann-Whitney test for two independent samples ( $\mathrm{z}=4.128)$} \\
\hline \multicolumn{11}{|l|}{ (b) Age groups } \\
\hline Age groups & \multicolumn{2}{|c|}{ Benign* } & \multicolumn{3}{|c|}{ Malignant* } & \multicolumn{2}{|l|}{ Total } & \multicolumn{2}{|l|}{ Test } & p-value \\
\hline $15-30$ years & \multicolumn{2}{|c|}{$13(100 \%, 44.83 \%)$} & \multicolumn{3}{|l|}{0} & \multicolumn{2}{|l|}{13} & \multicolumn{2}{|c|}{ Fischer exact } & 0.0002 \\
\hline $30-45$ years & \multicolumn{2}{|c|}{$13(81.25 \%, 44.83 \%)$} & \multicolumn{3}{|c|}{$3(18.75 \%, 27.27 \%)$} & \multicolumn{2}{|l|}{16} & & & \\
\hline $45-60$ years & \multicolumn{2}{|c|}{$2(25 \%, 6.9 \%)$} & \multicolumn{3}{|c|}{$6(75 \%, 54.55 \%)$} & \multicolumn{2}{|l|}{8} & & & \\
\hline $60-75$ years & \multicolumn{2}{|c|}{$1(33.33 \%, 3.45 \%)$} & \multicolumn{3}{|c|}{$2(66.67 \%, 18,18 \%)$} & \multicolumn{2}{|l|}{3} & & & \\
\hline Total & \multicolumn{2}{|c|}{29} & \multicolumn{3}{|c|}{11} & \multicolumn{2}{|l|}{40} & & & \\
\hline
\end{tabular}

*In 0 the first $\%$ is of respective age group while second $\%$ is of respective pathology category

Table 2: Frequency of distribution of breast lump according to the histopathological diagnosis

\begin{tabular}{|c|c|c|c|c|}
\hline Histopathology & Frequency & Percent & Exact $95 \%$ LCL & Exact $95 \%$ UCL \\
\hline Benign & 29 & 72.50 & 56.11 & 85.40 \\
\hline Fibroadenoma & 17 & 42.50 & 27.04 & 59.11 \\
\hline Fibroadenoma with atypia & 1 & 2.50 & 0.06 & 13.16 \\
\hline Fibrocystic disease & 2 & 5.00 & 0.61 & 16.92 \\
\hline Intraductal Papilloma & 1 & 2.50 & 0.06 & 13.16 \\
\hline Ductal Ectasias & 3 & 7.50 & 1.57 & 20.39 \\
\hline Lipoma & 1 & 2.50 & 0.06 & 13.16 \\
\hline Phyllodes & 1 & 2.50 & 0.06 & 13.16 \\
\hline Idiopathic Granulomatous mastitis & 1 & 2.50 & 0.06 & 13.16 \\
\hline Sclerosing adenitis & 1 & 2.50 & 0.06 & 13.16 \\
\hline Malignant & 11 & 27.50 & 14.60 & 43.89 \\
\hline IDC & 6 & 15.00 & 5.71 & 29.84 \\
\hline Ductal carcinoma in situ & 2 & 5.00 & 0.61 & 16.92 \\
\hline Medullary carcinoma & 2 & 5.00 & 0.61 & 16.92 \\
\hline Malignant lymph node & 1 & 2.50 & 0.06 & 13.16 \\
\hline
\end{tabular}

IDC: Invasive ductal carcinoma

the study population. The mean age of the cases was 37.28 years with a standard deviation of 13.21. The malignant masses were present significantly higher in older age groups than the benign as shown in Table $1 \mathrm{a}$ and $\mathrm{b}$.

\section{Histopathology of lump masses}

The histopathological report (Table 2) showed that fibroadenoma followed by fibrocystic disease was the most common benign pathology and IDC followed by ductal carcinoma in situ was the most common malignant pathology in patients presenting with palpable breast lumps.

\section{BIRADS Ultrasound and other descriptors}

Antiparallel placement (taller than wider), Spiculation-micro lobulation, Posterior acoustic shadow, presence of microcalcifications, internal vascularity, and axillary lymphadenopathy are the characteristics which were significantly higher present in malignant than benign masses. No significant difference was found in hypoechoic dominance in the two groups (Table 3a).

In this study, the descriptors antiparallel placement, spiculations, microcalcifications, and Posterior acoustic shadow have shown more than $95 \%$ specificity, more than $80 \%$ PPV and fall in Rule in category which means that if present than it is a malignant lesion, while hypoechoic dominance has a high sensitivity, high NPV and falls in rule out category which means that if not present than it rules out malignancy. But as spiculations, microcalcifications, posterior acoustic shadow, and hypoechoic dominance have a Youden index less than
$50 \%$; hence, the parameter does not meet empirical benchmarks for being used for diagnostic purposes. Internal vascularity and axillary lymphadenopathy have near 90\% NPV and a good PPV may strongly indicate toward malignancy [Table $3 \mathrm{~b}$ ].

Diagnostic cutoff values and diagnostic utility parameters of procedures

The cutoff values and diagnostic utility parameters of BIRADS, strain elastography, and SR were calculated for the study [Tables 4(a-c) and 5], [Figure 2].

In our study, the cutoff values (maximum Sensitivity +Specificity) are BIRADS III, ES of 3 and SR of 3. These cutoffs are similar to the cutoff values in the standards literature and scoring system for BIRADS and strain elastography.

In the study, the diagnostic utility indicators are summarized in Table 6 show that the indicators of strain elastography are better than that of BIRADS, while those of SR are better than BIRADS and strain elastography.

Correlation of conventional ultrasound, strain elastography, and SR with histopathology

- Conventional ultrasound (BIRADS) and Histopathology: With the cutoff value of BIRADS III, out of 29 benign lesions 25 were diagnosed as benign while four lesions showed BIRADS IV or more. While eight masses with BIRADS IV and V were diagnosed, as malignant out of 11 
Table 3a: Frequency of ultrasound and other descriptors in benign and malignant groups

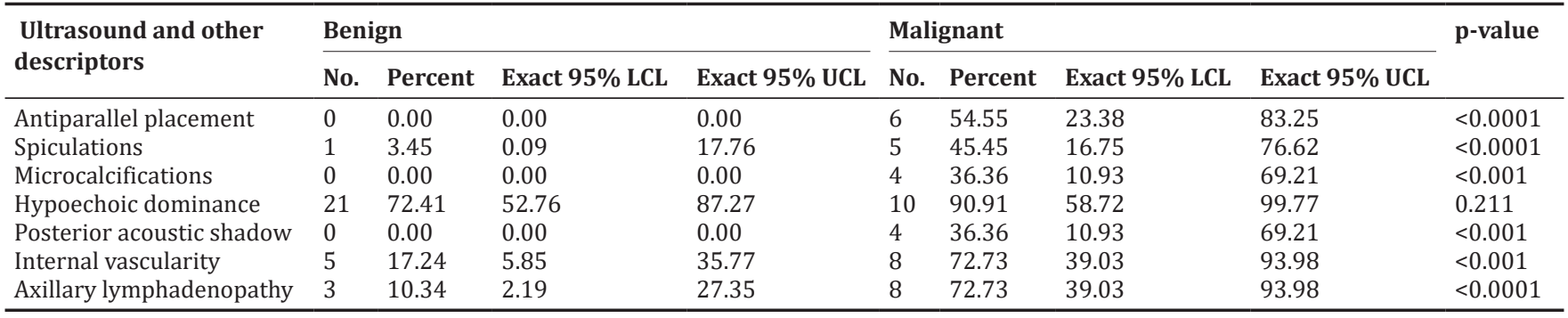

Table 3b: Diagnostic utility parameters of ultrasound and other descriptors

\begin{tabular}{|c|c|c|c|c|c|c|c|c|}
\hline $\begin{array}{l}\text { Ultrasound and other } \\
\text { descriptors }\end{array}$ & Sensitivity \% & Specificity \% & Youden index \% & "Rule in" & "Rule out" & PPV \% & $\begin{array}{l}\text { Negative } \\
\text { predictive value } \%\end{array}$ & $\begin{array}{l}\text { Accuracy } \\
\%\end{array}$ \\
\hline Antiparallel placement & 54.55 & 100.00 & 54.55 & True & False & 100.00 & 85.29 & 87.50 \\
\hline Spiculations & 45.45 & 96.55 & 42.01 & True & False & 83.33 & 82.35 & 82.50 \\
\hline Microcalcifications & 36.36 & 100.00 & 36.36 & True & False & 100.00 & 80.56 & 82.50 \\
\hline Hypoechoic dominance & 90.91 & 27.59 & 18.50 & False & True & 32.26 & 88.89 & 45.00 \\
\hline Posterior acoustic shadow & 36.36 & 100.00 & 36.36 & True & False & 100.00 & 80.56 & 82.50 \\
\hline Internal vascularity & 72.73 & 82.76 & 55.49 & False & False & 61.54 & 88.89 & 80.00 \\
\hline
\end{tabular}

PPV: Positive predictive value

proven malignant cases. Three malignant cases had been categorized as probably benign with $\leq$ BIRADS III. This was statistically significant (Fisher exact, $\mathrm{p}<0001$ )

- Correlation of Elastography using ES and Histopathology: 27 of the 29 benign masses had an ES 3 or less which was the cutoff. Two cases with ES 4 were found out to be benign. On the other hand, two with a score of 3 were malignant besides other 9 who had a score of 4 (5 masses) and 5 (4masses). This was statistically significant (Fisher exact, $\mathrm{p}<0001$ )

- Correlation of SR and Histopathology: The mean SR of the study population and histopathology groups of benign and malignant is shown in Table 7 [Figure 3].

From Table 4c, the cutoff value of SR is 3. Hence, at this level, 27 of the 29 diagnosed benign cases had value less than or equal to 3 while two of them had SR $>3$. All the diagnosed malignant cases had an SR value $>3$. This was statistically significant (Fisher exact, $\mathrm{p}<0.001$ ).

- Correlation of conventional ultrasound (BIRADS) and elastography using ES: Out of the 29 benign cases 25 had both BIRADS III or less and ES of 3 or less. While among the 4 benign cases who had BIRADS more than 3, two cases had an ES $<3$. On the other had among the histopathologically diagnosed malignant lesions, seven both had $>$ BIRADS III and ES >3; two cases with $\leq$ BIRADS III had an ES>3, one case had $>$ BIRAD III but ES $<3$; and one case had both BIRADS III and ES 3. Both the finding in benign and malignant groups were statistically significant (Kendell's rank correlation test; $\mathrm{p}<0.001$ )

- Correlation of conventional ultrasound (BIRADS) and SR: 25 cases of benign pathology had both $\leq$ BIRAD III and SR $\leq 3,2$ cases had $>$ BIRAD III but $\mathrm{SR} \leq 3$ and remaining 2 cases had both $>$ BIRAD III and $\mathrm{SR}>3$. In the malignant group, all cases had an $\mathrm{SR}>3$ but 3 cases had BIRAD III. (Statistically significant for benign, Fisher exact, $\mathrm{p}<0.05$ )

- Correlation of elastography using ES and SR: 27 cases of benign pathology had both $\mathrm{ES} \leq 3$ and $\mathrm{SR} \leq 3$, and 2 cases had both $\mathrm{ES}>3$ and $S R>3$. In the malignant group all cases had an $S R>3$ but 2 cases had $\mathrm{ES} \leq 3$. (Statistically significant for benign, Fisher exact, $\mathrm{p}<0.05$ ).

Discordant cases from correlation observation

The cases who had discordant values than for benign and malignant diagnostic modalities are summarized in Table 8a and b.

From Table 8a, if ES or SR was combined with BIRADS, 2 of the benign lesions would have been labeled as benign before histopathology. This in practical terms means a reduction of $25 \%$ in BIRADS IV (total eight patients) FNAC/Biopsies in this study presuming that all BIRAD Cases above BIRAD III are subjected to FNAC/Biopsy.
Table 4a: Diagnostic cutoff values and diagnostic utility parameters of BIRADS

\begin{tabular}{lllll}
\hline BIRADS category $\rightarrow$ & $\begin{array}{l}\text { BIRADS } \\
\text { II }\end{array}$ & $\begin{array}{l}\text { BIRADS } \\
\text { III }\end{array}$ & $\begin{array}{l}\text { BIRADS } \\
\text { IV }\end{array}$ & $\begin{array}{l}\text { BIRADS } \\
\text { V }\end{array}$ \\
\hline Sensitivity & $65.5 \%$ & $86.2 \%$ & $100.0 \%$ & $100.0 \%$ \\
Specificity & $90.9 \%$ & $72.7 \%$ & $36.4 \%$ & $0.0 \%$ \\
PPV & $95.0 \%$ & $89.3 \%$ & $80.6 \%$ & $72.5 \%$ \\
Negative predictive value & $50.0 \%$ & $66.7 \%$ & $100.0 \%$ & \\
Sensitivity + Specificity & $156.4 \%$ & $158.9 \%$ & $136.4 \%$ & $100.0 \%$ \\
Accuracy & $72.5 \%$ & $82.5 \%$ & $82.5 \%$ & $72.5 \%$ \\
Youden index & $56.4 \%$ & $58.9 \%$ & $36.4 \%$ & $0.0 \%$ \\
Kappa & $45.0 \%$ & $57.3 \%$ & $45.3 \%$ & $0.0 \%$ \\
\hline
\end{tabular}

BIRADS: Breast imaging reporting and data system, PPV: Positive predictive value

Table 4b: Diagnostic cutoff values and diagnostic utility parameters of strain elastography using ES

\begin{tabular}{lllll}
\hline ES $\rightarrow$ & ES 2 & ES 3 & ES 4 & ES 5 \\
\hline Sensitivity & $72.4 \%$ & $93.1 \%$ & $100.0 \%$ & $100.0 \%$ \\
Specificity & $100.0 \%$ & $81.8 \%$ & $36.4 \%$ & $0.0 \%$ \\
PPV & $100.0 \%$ & $93.1 \%$ & $80.6 \%$ & $72.5 \%$ \\
Negative predictive value & $57.9 \%$ & $81.8 \%$ & $100.0 \%$ & \\
Sensitivity +Specificity & $172.4 \%$ & $174.9 \%$ & $136.4 \%$ & $100.0 \%$ \\
Accuracy & $80.0 \%$ & $90.0 \%$ & $82.5 \%$ & $72.5 \%$ \\
Youden Index & $72.4 \%$ & $74.9 \%$ & $36.4 \%$ & $0.0 \%$ \\
Kappa & $59.1 \%$ & $74.9 \%$ & $45.3 \%$ & $0.0 \%$ \\
\hline
\end{tabular}

ES: Elastography score, PPV: Positive predictive value

Table 4c: Diagnostic cutoff values and diagnostic utility parameters of SR

\begin{tabular}{|c|c|c|c|c|c|c|}
\hline $\begin{array}{l}\text { Strain } \\
\text { Ratio } \rightarrow\end{array}$ & SR 1 & SR 2 & SR 3 & SR 4 & SR 5 & SR 6 \\
\hline Sensitivity & $17.2 \%$ & $55.2 \%$ & $93.1 \%$ & $96.6 \%$ & $96.6 \%$ & $100.0 \%$ \\
\hline Specificity & $100.0 \%$ & $100.0 \%$ & $100.0 \%$ & $72.7 \%$ & $63.6 \%$ & $27.3 \%$ \\
\hline PPV & $100.0 \%$ & $100.0 \%$ & $100.0 \%$ & $90.3 \%$ & $87.5 \%$ & $78.4 \%$ \\
\hline $\begin{array}{l}\text { Negative } \\
\text { predictive } \\
\text { value }\end{array}$ & $31.4 \%$ & $45.8 \%$ & $84.6 \%$ & $88.9 \%$ & $87.5 \%$ & $100.0 \%$ \\
\hline $\begin{array}{l}\text { Sensitivity } \\
+ \text { Specificity }\end{array}$ & $117.2 \%$ & $155.2 \%$ & $193.1 \%$ & $169.3 \%$ & $160.2 \%$ & $127.3 \%$ \\
\hline Accuracy & $40.0 \%$ & $67.5 \%$ & $95.0 \%$ & $90.0 \%$ & $87.5 \%$ & $80.0 \%$ \\
\hline Youden index & $17.2 \%$ & $55.2 \%$ & $93.1 \%$ & $69.3 \%$ & $60.2 \%$ & $27.3 \%$ \\
\hline Карра & $10.3 \%$ & $40.4 \%$ & $88.1 \%$ & $73.4 \%$ & $65.8 \%$ & $35.2 \%$ \\
\hline
\end{tabular}

SR: Strain ratio, PPV: Positive predictive value 
Similarly in Table 8b, three malignant lesions would have been missed if BIRAD III were not subjected to biopsy it means that approx. $27 \%$ of would have been missed. But if combined with ES two cases of three would have been biopsied resulting $<10 \%$ of cases would remain undiagnosed; but with SR all three cases would have been biopsied in this study.

One malignant case had ES $\leq 3$ with BIRADS IV; this was again clarified with SR and the patient lump would have been biopsied.

From Table 9, its evident that using BIRADS or ES in combination with SR is better than that of BIRADS and ES combined. And using SR in BIRADS or ES where SR and BIRADS/ES are in discordant in labeling benign/malignant lesion is better than combining the two.

Taking the above discordant cases as in Table 8a using SR, 2 of the BIRADS labeled malignant would have been labeled as benign before histopathology. While in Table 8b, all the discordant cases whether with BIRADS or ES would have been labeled malignant.

\section{DISCUSSION}

Breast cancer has a high mortality rate due to the higher stages of malignancy at the time of diagnosis. Hence, more accurate modalities for better diagnosis are required to be used in the primary stages. In the present study, we used SE additionally to conventional B-mode ultrasound imaging. Two different features of SE were included in our results ES and SR.

Table 5: ROC analysis of BIRADS, strain elastography using ES and SR

\begin{tabular}{|c|c|c|c|}
\hline Feature & BIRADS & $\begin{array}{l}\text { Strain elastography } \\
\text { using ES }\end{array}$ & Strain ratio \\
\hline $\begin{array}{l}\text { Area under the } \\
\text { ROC curve (AUC) }\end{array}$ & 0.870 & 0.953 & 0.980 \\
\hline Standard error & 0.0660 & 0.0277 & 0.0198 \\
\hline $\begin{array}{l}95 \% \text { confidence } \\
\text { interval }\end{array}$ & $0.726-0.955$ & $0.835-0.995$ & $0.876-1.000$ \\
\hline Z statistic & 5.605 & 16.348 & 24.256 \\
\hline $\begin{array}{l}\text { Significance level } \\
\mathrm{P}(\text { Area }=0.5)\end{array}$ & $<0.0001$ & $<0.0001$ & $<0.0001$ \\
\hline
\end{tabular}

SR: Strain ratio, BIRADS: Breast imaging reporting and data system

Table 6: Summary of diagnostic utility indicators

\begin{tabular}{llll}
\hline $\begin{array}{l}\text { Diagnostic Utility } \\
\text { Indicators }\end{array}$ & BIRADS & $\begin{array}{l}\text { Strain elastography } \\
\text { using ES }\end{array}$ & SR \\
\hline Sensitivity & $86.2 \%$ & $93.1 \%$ & $93.1 \%$ \\
Specificity & $72.7 \%$ & $81.8 \%$ & $100.0 \%$ \\
PPV & $89.3 \%$ & $93.1 \%$ & $100.0 \%$ \\
Negative predictive value & $66.7 \%$ & $81.8 \%$ & $84.6 \%$ \\
Sensitivity + Specificity & $158.9 \%$ & $174.9 \%$ & $193.1 \%$ \\
Accuracy & $82.5 \%$ & $90.0 \%$ & $95.0 \%$ \\
Youden index & $58.9 \%$ & $74.9 \%$ & $93.1 \%$ \\
Kappa & $57.3 \%$ & $74.9 \%$ & $88.1 \%$ \\
AUC & 0.870 & 0.953 & 0.980 \\
\hline
\end{tabular}

SR: Strain ratio, BIRADS: Breast imaging reporting and data system, PPV:

Positive predictive value
Lesions graded as BIRADS 3 are probably benign and short term follow-up is recommended. Nevertheless, malignancy is eventually diagnosed in about $3 \%$ of these lesions resulting in delayed diagnosis of cancer in a considerable number of patients [13]

In our study, the malignant masses were present in older age groups and with higher mean age than the benign. This age statistics is comparable with the present trend in the incidence of breast cancer among Indian women which is in increasing numbers of female from 25 to 40 years of age as stated by Sandhu et al. [14] and Somdatta et al. [15]

The present study revealed that the benign masses (72.5\%) are more frequent than malignant ones (27.5\%). Our study (Table 2) correlates with studies of Nigam et al. [16] and Phurailatpam et al. [17] which also show fibroadenoma followed by fibrocystic disease as the most common benign pathology and IDC followed by DCIS as the most common malignant pathology in patients presenting with palpable breast lumps.

The ultrasound descriptors in study, antiparallel placement, Spiculation-microlobulation, Posterior acoustic shadow, presence of microcalcifications, internal vascularity, and axillary lymphadenopathy are that the characteristics were found significantly in the malignant breast masses but due to low Youden index spiculations, microcalcifications and posterior acoustic shadow cannot be used for diagnostic purposes. Stavros et al.,[4] Constatini et al., [18] and Hong et al. [19] documented the characterization of solid breast masses and found these present in the malignant breast masses with high PPV.

We found that using BIRADS (with a sensitivity of $86.2 \%$ and specificity of $72.7 \%$ ) out of 40 cases, 33 (82.5\%) cases were diagnosed correctly as per histopathological grouping (benign and malignant) which increased to $36(90 \%)$ cases using ES in strain elastography (with a sensitivity of $93.1 \%$ and specificity of $81.8 \%$ ) and further to 38 (95\%) cases using SR in strain elastography (with a sensitivity of $93.1 \%$ and specificity of $100 \%$ ).

The diagnostic accuracy and AUC increased from 82.5\%, 0.870 with BIRADS to $90 \%, 0.953$ with ES and 95\%, 0.980 with SR respectively. SR has also been found better than ES and Conventional by Parajuly et al. and Thomas et al. Parajuly et al. reported a higher AUC with SR (0.96) than ES (0.90) and conventional ultrasound (0.88) while Thomas et al. had documented a sensitivity and specificity of $96 \%$ and $56 \%$ for B-mode scanning, $81 \%$ and $89 \%$ for elastography, and $90 \%$ and $89 \%$ for SR.

We found that combined use of B-mode USG with ES score or SR is more effective in differentiating malignant and benign lesions than sonography alone. Different combinations were tried using BIRADS, strain elastography using ES and SR (Table 9). The AUC increased from 0.870 using BIRADS alone to 0.886 while using BIRADS and ES combined and to 0.920 if ES was used in discordant cases only. On the other hand, AUC increased from 0.870 using BIRADS alone to 0.931 while using BIRADS and SR combined and to 0.961 if SR was used in discordant cases only. SR has shown better parameters than ES in this study.

Similar increase in AUC from BIRADS to combining it with ES was seen by Hao et al. [20] (0.73-0.87) and Yeo et al. (0.65-0.86) [21].

Table 7: Descriptive statistics of SR of study population and histopathology groups

\begin{tabular}{|c|c|c|c|c|c|c|c|c|c|c|c|}
\hline $\begin{array}{l}\text { Parameter } \\
\text { Assessed }\end{array}$ & Obs & Total & Mean & Var & Std Dev & Min & $25 \%$ & Median & $75 \%$ & Max & Mode \\
\hline Study population & 40 & 117.34 & 2.93 & 3.67 & 1.91 & 0.56 & 1.78 & 2.21 & 3.85 & 8.1 & 2.2 \\
\hline Benign* & 29 & 57.9 & 2.00 & 0.94 & 0.97 & 0.56 & 1.3 & 2 & 2.24 & 5.4 & 2.2 \\
\hline Malignant* & 11 & 59.44 & 5.40 & 2.41 & 1.55 & 3.5 & 3.9 & 5.2 & 6.7 & 8.1 & 3.5 \\
\hline
\end{tabular}

*Significant difference, Mann-Whitney Test for Two Independent Samples ( $\mathrm{z}=4.6208 ; \mathrm{p}<0.0001)$. SR: Strain ratio 
The cutoff values of the three diagnostic utilities in our study were BIRAD III for conventional ultrasound, ES of 3 for strain elastography and SR 3 for SR in strain elastography. The cutoff of BIRADS and ES was documented to be similar to that of BIRADS guidelines and scoring system, respectively [8].

SR cutoff was documented 1.90 by Ranjkesh et al., [22] 2.54 by Thomas et al., [9] 3.1 by Ozel et al., [23] 3.5 by Bojanic et al., [24] 3.54 by Parajuly et al., [25] 3.65 by Gheonea et al., [26] 4.15 by Li et al., [27] 4.8 by Barr et al., [28] and 5.6 by Alhabshi et al. [29]

The variation in the cutoff values among these studies $1.90-5.6$ can be a result of pre-compression, especially by a radiologist with inadequate clinical experience $[24,30]$. Pre-compression increases the stiffness of all tissues hence changing the strain value of fat. This stiffness variation in fat tissue is more prominent than those in normal breast tissue and masses; thus, with pre-compression, the SR will decrease [24]. The other reason that could explain the SR results obtained in our and other studies is ROI inconsistency [24] and movement of patient [9] during procedure besides this variation in SR can be attributed to the different equipment used [22].

Another aspect of the study was the type of lesions that were discordant on different diagnostic utilities.

In our study, the benign lesion which was diagnosed as malignant, that is, false-positive lesions is IGM, Sclerosing adenitis, a fibroadenoma and

Table 8a: Different diagnostic values of discordant benign cases

\begin{tabular}{llllll}
\hline Cases & Histopathology & BIRADS & ES & SR & $\begin{array}{l}\text { Antiparallel } \\
\text { placement }\end{array}$ \\
\hline 1 & Phyllodes & IV & 4 & 5.34 & No \\
2 & Sclerosing adenitis & IV & 4 & 3.5 & No \\
3 & Fibroadenoma & IV & 3 & 2 & No \\
4 & Idiopathic & IV & 3 & 2.65 & No \\
& Granulomatous mastitis & & & & \\
\hline
\end{tabular}

BIRADS: Breast imaging reporting and data system

Table 8b: Different diagnostic values of discordant malignant cases

\begin{tabular}{llllll}
\hline Cases & Histopathology & BIRADS & ES & SR & $\begin{array}{l}\text { Antiparallel } \\
\text { placement }\end{array}$ \\
\hline 1 & Medullary Carcinoma & III & 4 & 4.3 & No \\
2 & Medullary Carcinoma & III & 3 & 3.5 & Yes \\
3 & Malignant Lymph Node & III & 4 & 3.8 & No \\
4 & IDC & IV & 3 & 3.69 & No \\
\hline
\end{tabular}

BIRADS: Breast imaging reporting and data system, IDC: Invasive ductal carcinoma phyllodes. IGM and fibroadenoma appeared soft on Elastography both with ES and SR. Sclerosing adenitis and phyllodes were false positive in all diagnostic utilities used.

Arslan et al. [31] reported that IGM was categorized BIRADS III on B-Mode USG based on its characteristics of irregular heterogeneously hypoechoic mass with tubular extensions. However, IGM appeared soft on SE with elasticity score of 2 and lower SR.

Chen et al. [32] reported that sclerosing adenitis is a benign proliferative disease which exhibits USG characteristics of malignancy such as calcifications, indistinct margins, PAS, and hypervascularity which contributed to the overestimation of this lesion on USG. Moukhtar et al. [3] reported that B-Mode USG revealed BIRADS score IV and Elasticity score 3 for Sclerosing adenitis.

Li et al. [33] reported approximately $25 \%$ of phyllodes masses reporting an ES score more than 3. Similar false-positive results with phyllodes were reported by Khanduri et al. [34]

Li et al. [33] has documented 5\% of fibroadenoma to have an ES more than 3 as compared to $5.8 \%$ reported in our study.

In our study, one case of Infiltrating ductal carcinoma - Adenoid cystic type (IDC-ACT) which was reported as BIRADS IV on B-Mode USG, displayed ES 3 and higher SR of 3.9.

Huang et al.,[35] Ichikawa et al., [36] and Tang et al. [37] stated that adenoid cystic carcinoma is a rare breast tumor which can mimic benign lesion on ultrasound. Elastography may be helpful in differentiating between malignancy and benignity.

In our study, we reported one case of adenoid cystic tumor which showed well defined margins with minimal internal vascularity, no calcification or no PAS and was reported as BIRADS III on B-Mode USG. On elastography it displayed ES 3 and higher SR of 3.9.

In our study, two cases of medullary carcinoma were discordant among diagnostic utilities. Jin et al. [38] stated that $60 \%$ of medullary carcinoma mimicked a benign appearance on B-mode USG and exhibited high stiffness on Strain elastography. Meyer et al. [39] stated that medullary carcinoma of breast appears as well defined, non-calcified mass with no PAS on B-mode ultrasound and mimics as benign mass.

One malignant lymph node was present among discordant masses (Table 8b). Choi et al. [40] reported that metastatic lymphadenopathy can be misdiagnosed as reactive adenitis on B-Mode USG. Strain elastography combined with B-mode USG increased the sensitivity of axillary lymph node metastasis

Table 9: Comparison of various diagnostic utility indicators using individual and combined parameters

\begin{tabular}{|c|c|c|c|c|c|c|}
\hline $\begin{array}{l}\text { Diagnostic utility } \\
\text { indicators }\end{array}$ & $\begin{array}{l}\text { Combined } \\
\text { BIRADS and SR* }\end{array}$ & $\begin{array}{l}\text { Combined } \\
\text { BIRADS and ES* }\end{array}$ & $\begin{array}{l}\text { Combined } \\
\text { ES and SR* }\end{array}$ & $\begin{array}{l}\text { Combined } \mathrm{E} \\
\text { BIRADS and } \mathrm{SR}^{* *}\end{array}$ & $\begin{array}{l}\text { Combined } \mathrm{E} \\
\text { BIRADS and ES** }\end{array}$ & $\begin{array}{l}\text { Combined E } \\
\text { ES and SR** }\end{array}$ \\
\hline Sensitivity & $86.21 \%$ & $86.21 \%$ & $93.10 \%$ & $93.10 \%$ & $93.10 \%$ & $93.10 \%$ \\
\hline Specificity & $100.00 \%$ & $90.91 \%$ & $100.00 \%$ & $100.00 \%$ & $90.91 \%$ & $100.00 \%$ \\
\hline PPV & $100.00 \%$ & $96.15 \%$ & $100.00 \%$ & $100.00 \%$ & $96.43 \%$ & $100.00 \%$ \\
\hline Negative predictive value & $73.33 \%$ & $71.43 \%$ & $84.62 \%$ & $84.62 \%$ & $83.33 \%$ & $84.62 \%$ \\
\hline Sensitivity + Specificity & 1.862 & 1.771 & 1.931 & 1.931 & 1.840 & 1.931 \\
\hline Accuracy & 0.900 & 0.875 & 0.950 & 0.950 & 0.925 & 0.950 \\
\hline Карра & 0.775 & 0.711 & 0.881 & 0.881 & 0.817 & 0.881 \\
\hline AUC & 0.931 & 0.886 & 0.966 & 0.966 & 0.920 & 0.966 \\
\hline
\end{tabular}

${ }^{*}$ Combination made by combining the common and either diagnosed histopathological groups by individual modalities. ${ }^{*}$ Combination made by combining common + ones with difference the superior finding prevailing, that is, SR prevails over ES and BIRADS while ES prevails over BIRADS, SR: Strain ratio, BIRADS: Breast imaging reporting and data system, PPV: Positive predictive value 


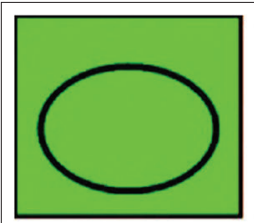

a.

a

\section{Tsukuba Elasticity} Score 1

\section{Tsukuba Elasticity Score 2}

\section{Tsukuba Elasticity Score 3}

\section{Tsukuba Elasticity Score 4}

\section{Tsukuba Elasticity Score 5 \\ b}

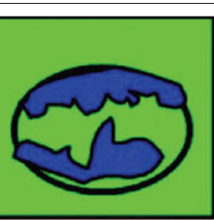

.
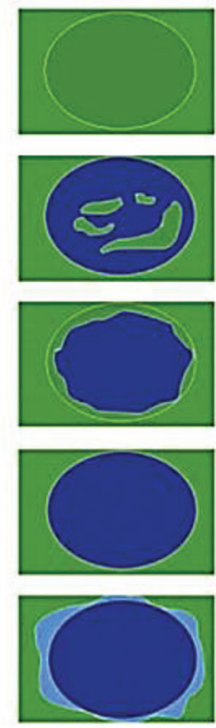

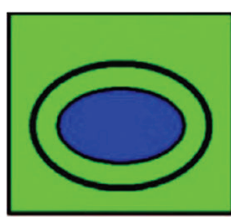

c.
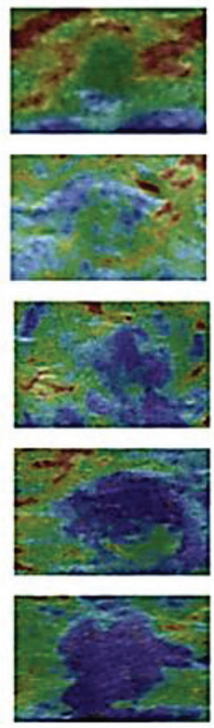

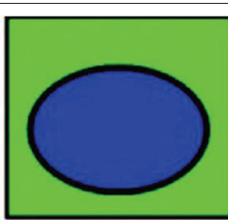

d.

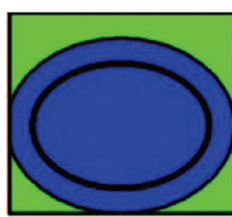

e.

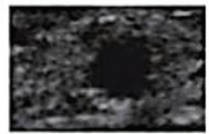

benign

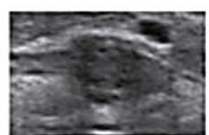

benign

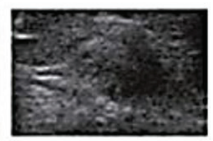

probably benign

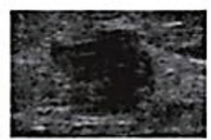

malignant

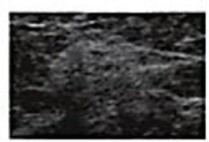

malignant

Figure 1: (a-b): 5-point TSUKUBA Scoring method*. *Images present general appearance of lesions for elasticity scores of (a) 1, (b) 2, (c) 3, (d) 4, and (e) 5 . Black circle indicates outline of hypoechoic lesion (i.e., border between lesion and surrounding breast tissue) on B-mode images [8]. **Breast elastography images are classified in five categories (Tsukuba elasticity scores 1-5) based on strain image patterns superimposed on B-mode images. Lesions scored 1 or 2 are considered benign, lesions scored 3 are considered to be probably benign and lesions scored 4 or 5 are considered malignant [11]
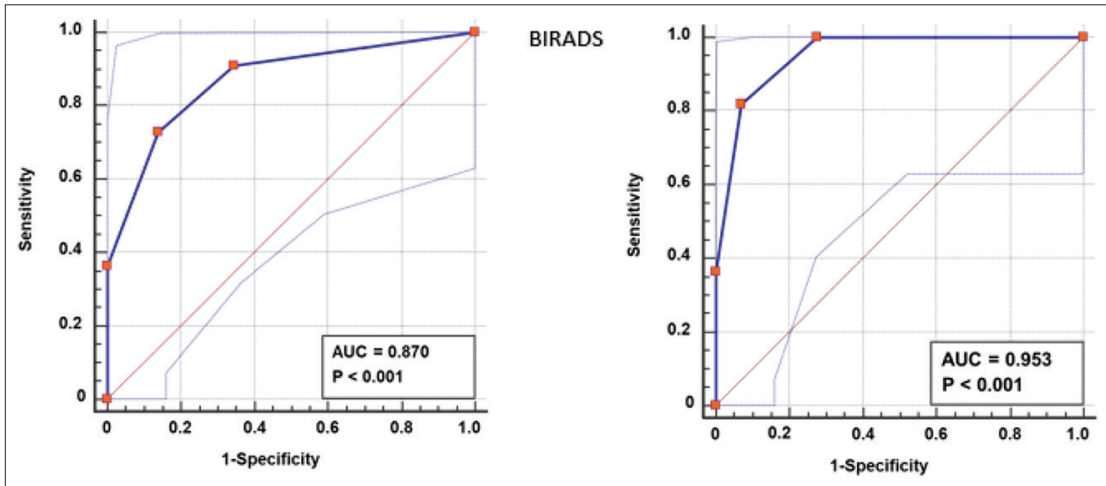

ES

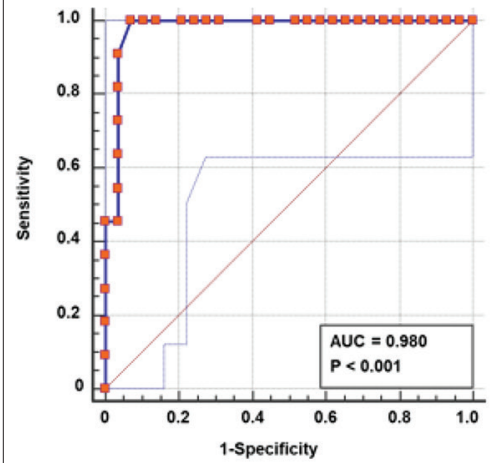

$S R$

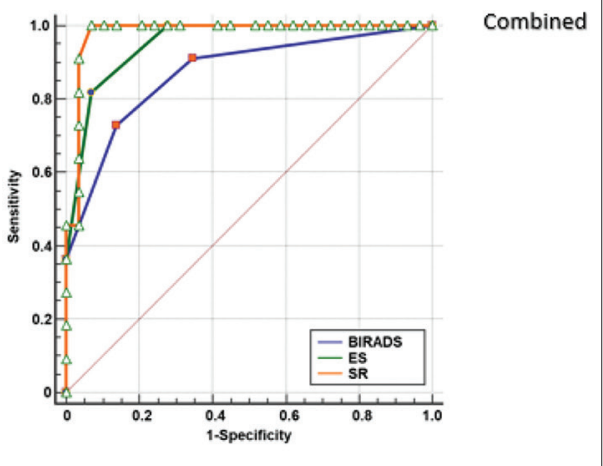

Figure 2: ROC of breast imaging reporting and data system, strain elastography using ES and strain ratio 


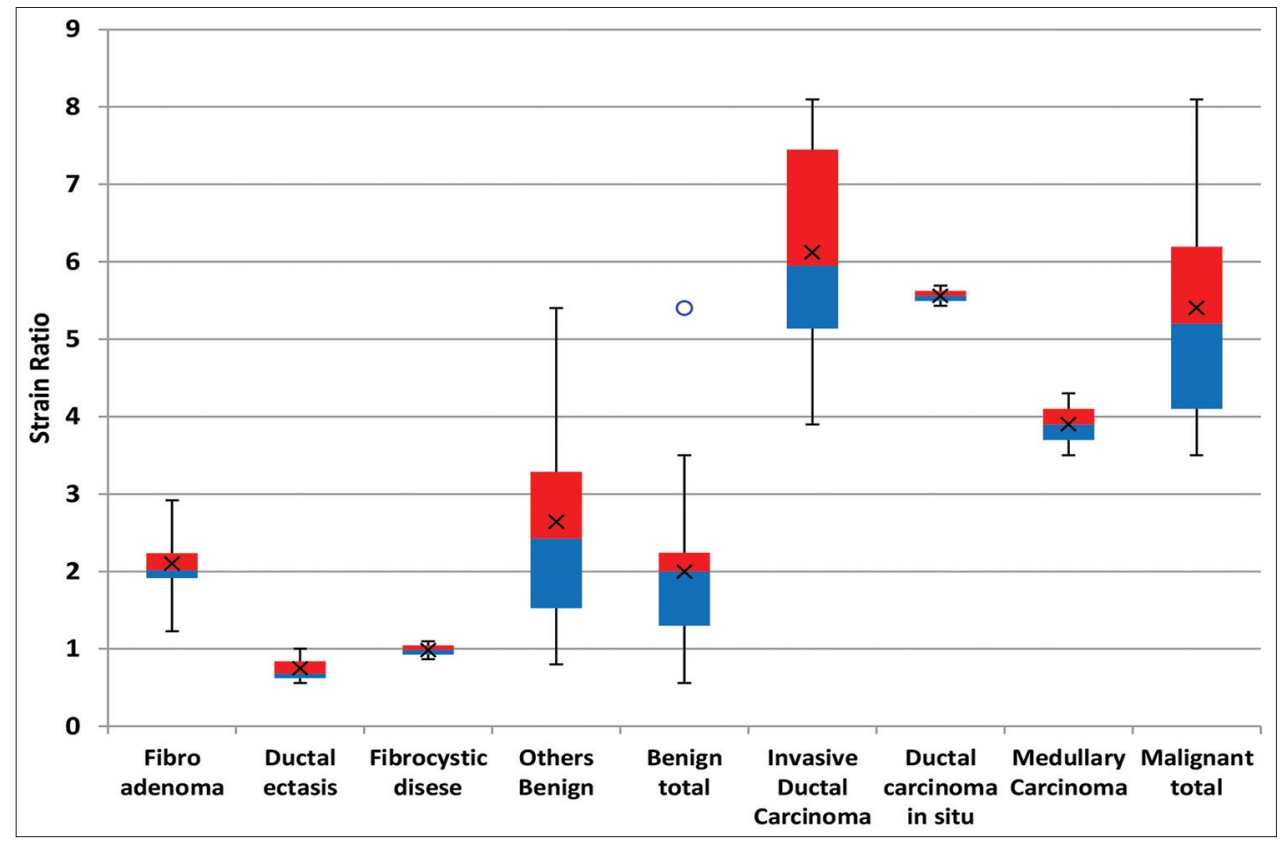

Figure 3: Boxplot graphs demonstrating a difference in elastography strain ratio for different breast lesions. Whiskers and lines delineate $\mathbf{9 5 \%}$ confidence intervals

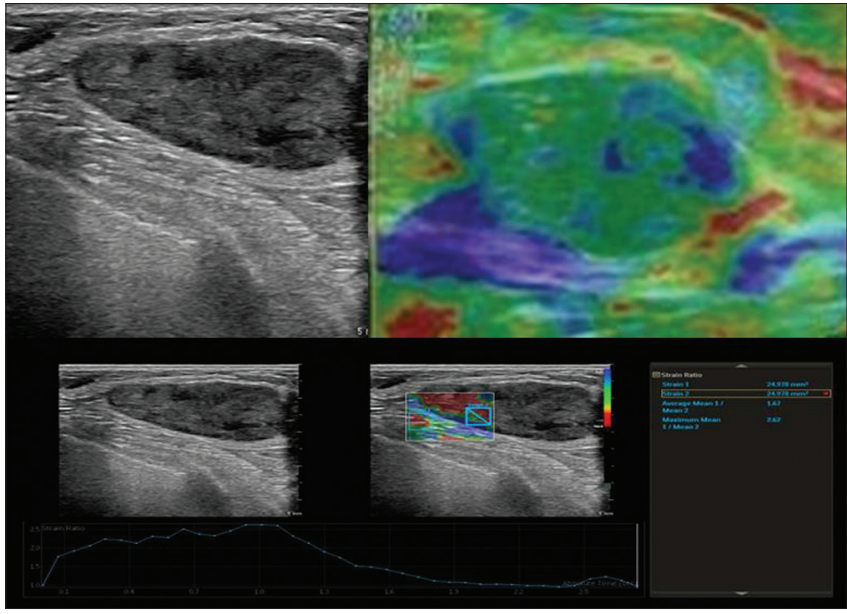

Figure 4: Case 1: Fibroadenoma

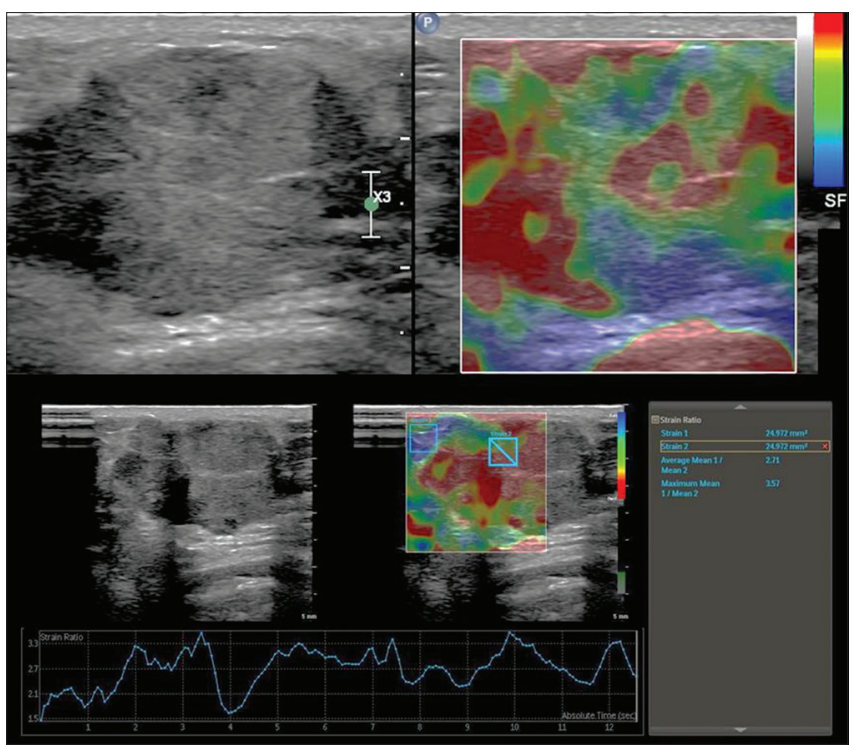

Figure 5: Case 2: Medullary carcinoma

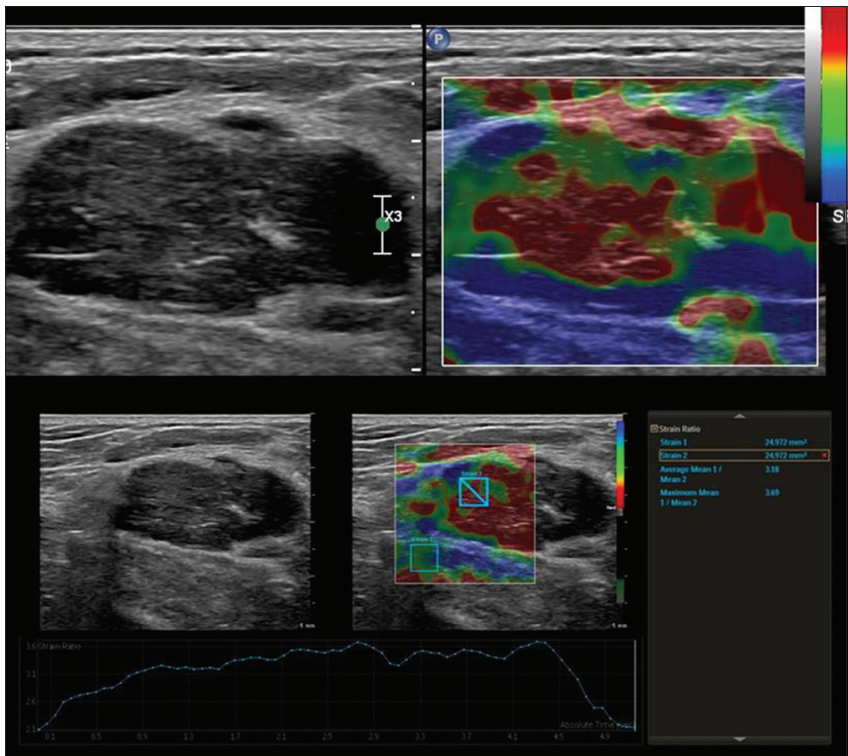

Figure 6: Case 3: Adenoid cystic carcinoma

Table 10: Disagreement Pattern and proposed diagnostic utility addition

\begin{tabular}{llll}
\hline BIRADS & Discordant masses & ES & SR \\
\hline II & No disagreement & & \\
III & Yes & Add & Add \\
IV & Yes & Add & Add \\
V & No disagreement & & \\
\hline
\end{tabular}

SR; Strain ratio, BIRADS: Breast imaging reporting and data system, ES: Elastography score

detection. Sonographic elastography is helpful in differentiating reactive and metastatic axillary lymph nodes.

Ozel et al. [23] calculated the mean SR for benign lesions was as $2.1 \pm 1.6$ (mean \pm standard deviation) and malignant lesions was $4.6 \pm 2.6$ while Bojanic et al. [24] documented that mean SR for the benign lesions was $2.3(1.5-3.1)$ and for malignant lesions was 4.9 (3.8-6.1). Other studies 


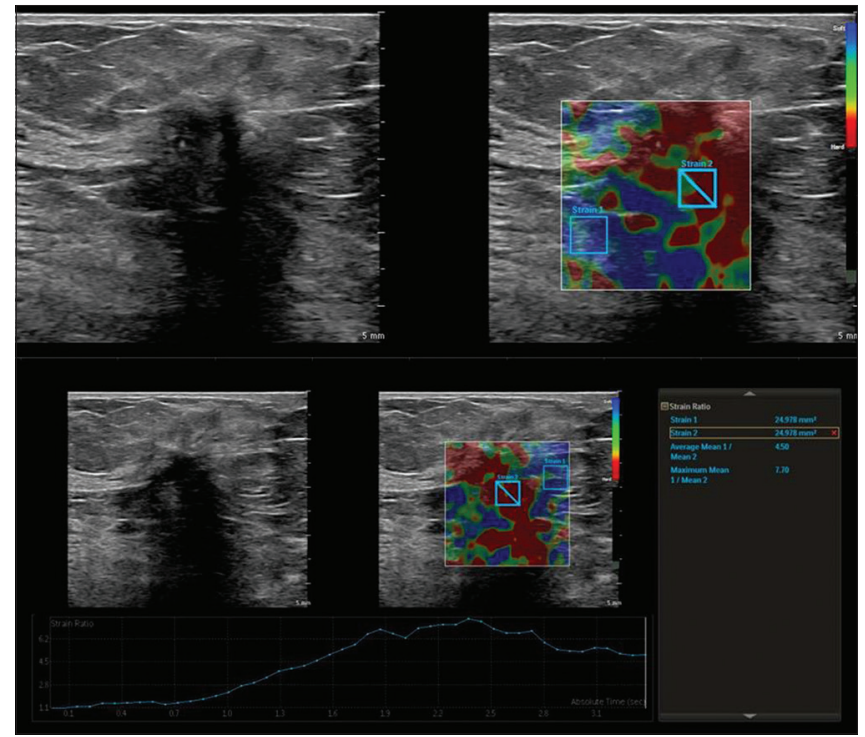

Figure 7: Case 4: Invasive ductal carcinoma

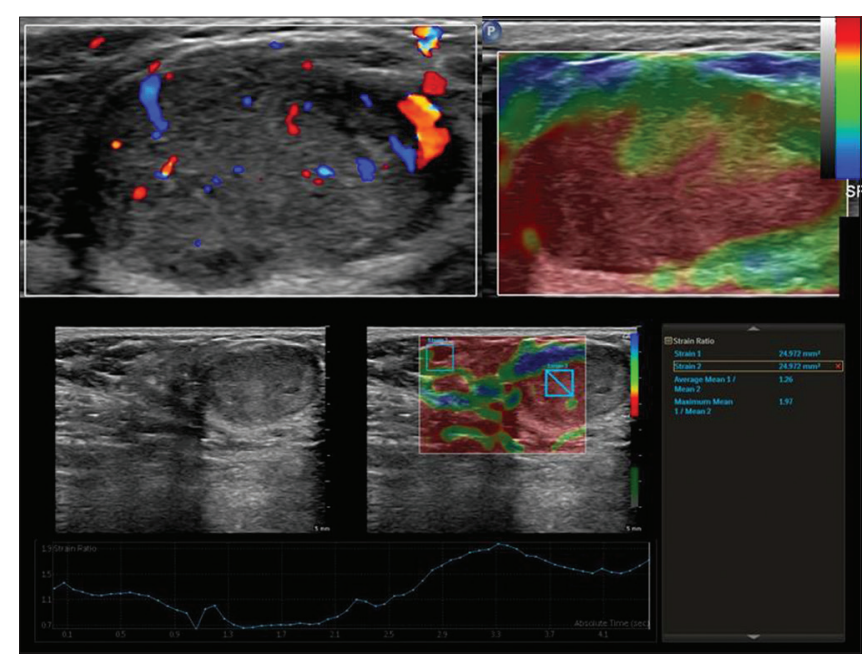

Figure 8: Case: 5: Fibroadenoma with atypia

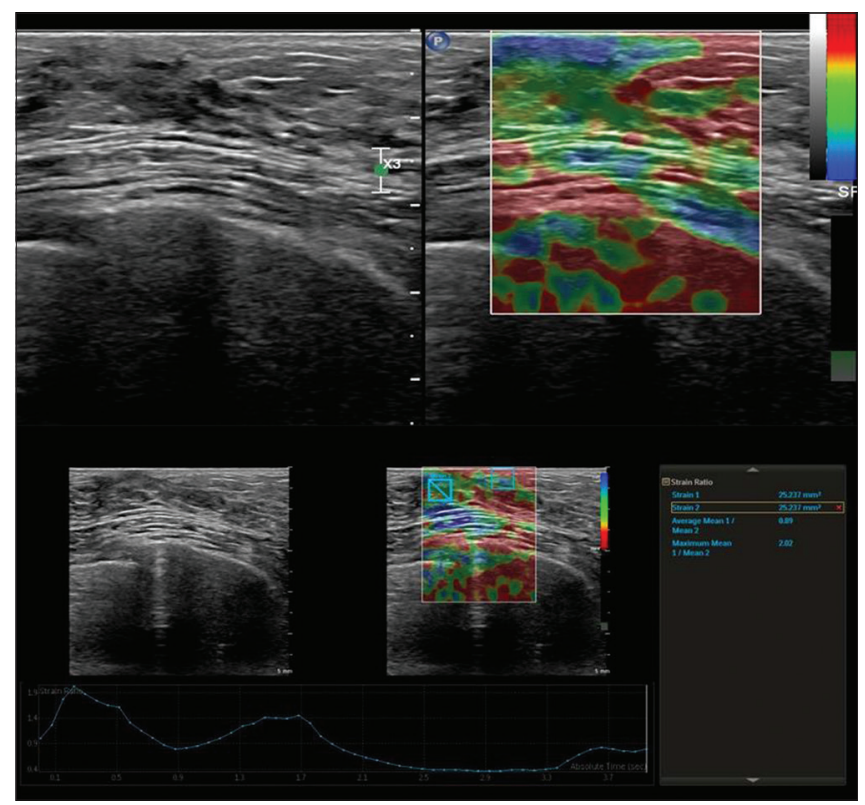

Figure 9: Case: 6: Nodular gynecomastia had shown varied SR for malignant lesions as $3.02 \pm 1.3$ in Lee et al. [6] and 7.9 $\pm 5.8 \mathrm{Mu}$ et al. [41]

Strain elastography as an imaging modality requires external compression, applied manually, hence is operator dependent, which influences its reproducibility. Yerli et al. [42] in a study concluded that after evaluation of lesions with the Tsukuba elasticity scoring system, additional evaluation of the SR increased calculation time and did not contribute significantly to the differentiation between benign and malignant lesions. Menezes et al. [30] assessed four elastography criteria (ES, SR, distance ratio, and area ratio) and reported that all four were able to differentiate benign and malignant lesions, but the ES was the most accurate. This is in agreement with our results that either ES or SR was able to differentiate benign and malignant lesions with statistical significance.

In our study, the disagreement/discordant masses fell in two categories of BIRADS, that is, BIRAD III and IV. If we add sonoelastography for these two categories the sensitivity and specificity show significant improvement; more if we use SR than ES [Table 10].

\section{CONCLUSION}

Ultrasound elastography was found to have high sensitivity, specificity, and diagnostic accuracy in differentiating benign and malignant breast masses than conventional B mode ultrasound. SR has shown potential to be used as a compliment to BIRADS better than ES. Using SR alone has shown better sensitivity, specificity, and diagnostic accuracy but its standalone or in combination diagnostic application has to be followed up with further studies.

\section{Some case discussions of study}

Case 1

24 years unmarried pre-menopausal female with painless lump left breast in the retro areolar region. Sonoelastography and B-mode US on split screen mode. B-mode USG revealed well defined smoothly marginated oval shaped hypodense lesion with no internal calcifications, no PAS, and no internal vascularity on color Doppler. No axillary lymphadenopathy was seen. BIRADS II. The strain elastography revealed the entire hypoechoic mass coded blue and green (Elasticity score 2 and SR of 2.6). This mass was considered as benign. Histopathological results proved a case of fibroadenoma [Figure 4].

Case 2

50 years married postmenopausal female presented with painless lump left breast in the Upper inner quadrant. Sonoelastography and B-mode US on split screen mode. B-Mode USG revealed a relatively well defined oval shaped hypodense mass in the upper inner quadrant with no internal calcifications or PAS. On CDFI internal vascularity is present. Axillary lymphadenopathy was seen. BIRADS III (probably benign). Elastography findings revealed mix pattern of blue green and red. The central part is harder than the periphery. The surrounding tissue displays blue color. Elasticity score 3 and SR- 3.5. This mass was considered as probably benign on B-Mode USG and equivocal on strain elastography. The histopathological results proved a case of Medullary Carcinoma [Figure 5].

\section{Case 3}

37 years old married premenopausal female with painless lump left breast in the retro areolar region. B-Mode USG revealed relatively well defined oval shaped hypodense mass in the retro areolar with no internal calcifications or PAS. On CDFI no internal vascularity is present. Axillary lymphadenopathy was seen. BIRADS III, that is, probably benign. Elastography revealed that the center of the mass is hard, that is, red in the center and soft at the periphery, that is, blue. Surrounding tissue also displays normal strain. Elasticity score 3 and SR- 3.69 Histopathology proved the mass was infiltrating ductal carcinoma adenoid cystic type (IDC-ACT) [Figure 6]. 
Case 4

60 years married postmenopausal female presented with painless lump left breast in the retro areolar region. USG revealed Ill well defined hypodense, taller than wider mass with spiculated margins showing internal microcalcifications and PAS in the retro areolar region. On CDFI, internal vascularity was present. Axillary lymphadenopathy was seen. BIRADS V (definitely malignant). Elastography findings revealed the entire mass was hard, that is, the entire mass is red with infiltration of the surrounding tissue at places - Elasticity score 5 and SR- 7.7. Histopathology proved the mass as infiltrating ductal carcinoma (IDC) [Figure 7].

Case 5

63 years married postmenopausal female with painless lump right breast in the UOQ.USG revealed well defined, lobulated, oval shaped hypodense mass with lobulated margins showing no internal microcalcifications and PAS in the right upper outer quadrant. On CDFI, internal vascularity was present. Axillary lymphadenopathy was not seen. BIRADS IV, that is, probably malignant. Elastography revealed mixed strain of blue green and red. Elasticity score 3 and SR-1.9. The mass was considered benign on elastography. Histopathology proved the mass as fibroadenoma with atypia [Figure 8].

Case 6

50 years male presented with lump in the retro areolar regions revealed Ill-defined hypoechoic mass with no internal calcifications or PAS in the left retro areolar region. On CDFI, internal vascularity was absent. Axillary lymphadenopathy was not seen. BIRADS III, that is, probably benign. Elastography revealed the entire lesion is soft and displays blue color - Elasticity score 2 and SR- 2.02. It was considered benign on elastography. Histopathology proved it to be Nodular gynecomastia [Figure 9].

\section{REFERENCES}

1. Klein S. Evaluation of palpable breast masses. Am Fam Physician 2005;71:1731-8

2. Sung H, Ferlay J, Siegel RL, Laversanne M, Soerjomataram I, Jemal A, et al. Global cancer statistics 2020: GLOBOCAN estimates of incidence and mortality worldwide for 36 cancers in 185 countries. CA Cancer J Clin 2021;71:209-49.

3. Moukhtar FZ, ElMaati AA. Real-time tissue elastography combined with BIRADS-US classification system for improving breast lesion evaluation. Egypt J Radiol Nuclear Med 2014;45:1021-8.

4. Stavros AT, Thickman D, Rapp CL, Dennis MA, Parker SH, Sisney GA. Solid breast nodules: Use of sonography to distinguish between benign and malignant lesions. Radiology 1995;196:123-34.

5. Mainiero MB, Goldkamp A, Lazarus E, Livingston L, Koelliker SL, Schepps B, et al. Characterization of breast masses with sonography: Can biopsy of some solid masses be deferred? J Ultrasound Med 2005;24:161-7.

6. Lee WJ, Chu JS, Huang CS, Chang MF, Chang KJ, Chen KM. Breast cancer vascularity: Color Doppler sonography and histopathology study. Breast Cancer Res Treat 1996;37:291-8.

7. Goddi A, Bonardi M, Alessi S. Breast elastography: A literature review. J Ultrasound 2012;15:192-8.

8. Itoh A, Ueno E, Tohno E, Kamma H, Takahashi H, Shiina T, et al. Breast disease: Clinical application of us elastography for diagnosis. Radiology 2006;239:341-50.

9. Thomas A, Degenhardt F, Farrokh A, Wojcinski S, Slowinski T, Fischer T. Significant differentiation of focal breast lesions: Calculation of strain ratio in breast sonoelastography. Acad Radiol 2010;17:558-63.

10. Imtiaz S. Breast elastography: A new paradigm in diagnostic breast imaging. Appl Radiol 2018;47:14-9.

11. Schwab F, Redling K, Siebert M, Schötzau A, Schoenenberger CA, Zanetti-Dällenbach R. Inter-and intra-observer agreement in ultrasound BI-RADS classification and real-time elastography Tsukuba score assessment of breast lesions. Ultrasound Med Biol 2016;42:2622-9.

12. MedCalc ${ }^{\circledR}$. Statistical Software Version 20.006. Ostend, Belgium: MedCalc Software Ltd. Available from: https://www.medcalc.org; 2021.

13. Sadigh G, Carlos RC, Neal CH, Dwamena BA. Accuracy of quantitative ultrasound elastography for differentiation of malignant and benign breast abnormalities: A meta-analysis. Breast Cancer Res Treat 2012;134:923-31.

14. Sandhu DS, Sandhu S, Karwasra RK, Marwah S. Profile of breast cancer patients at a tertiary care hospital in north India. Indian J Cancer 2010;47:16-22.

15. Somdatta $P$, Baridalyne N. Awareness of breast cancer in women of an urban resettlement colony. Indian J Cancer 2008;45:149-53.

16. Nigam M, Nigam B. Triple assessment of breast-gold standard in mass screening for breast cancer diagnosis. IOSR J Dent Med Sci 2013;7:1-7.

17. Phurailatpam AS, Prasad CS, Kishore Kumar BN, Hegde P. Evaluation of mammography, sonomammography in correlation with fine needle aspiration of breast lumps. Int J Biol Med Res 2014;5:4370-6.

18. Costantini M, Belli P, Lombardi R, Franceschini G, Mulè A, Bonomo L. Characterization of solid breast masses: Use of the sonographic breast imaging reporting and data system lexicon. J Ultrasound Med 2006;25:649-59.

19. Hong AS, Rosen EL, Soo MS, Baker JA. BI-RADS for sonography: Positive and negative predictive values of sonographic features. AJR Am J Roentgenol 2005;184:1260-5.

20. Hao SY, Jiang QC, Zhong WJ, Zhao XB, Yao JY, Li LJ, et al. Ultrasound elastography combined with BI-RADS-US classification system: Is it helpful for the diagnostic performance of conventional ultrasonography? Clin Breast Cancer 2016;16:e33-41.

21. Yeo SH, Kim GR, Lee SH, Moon WK. Comparison of ultrasound elastography and color Doppler ultrasonography for distinguishing small triple-negative breast cancer from fibroadenoma. J Ultrasound Med 2018;37:2135-46.

22. Ranjkesh M, Hajibonabi F, Seifar F, Tarzamni MK, Moradi B, Khamnian Z. Diagnostic value of elastography, strain ratio, and elasticity to B-mode ratio and color Doppler ultrasonography in breast lesions. Int J Gen Med 2020;13:215-24

23. Özel D, Özel BD. Evaluating the role of strain ratio elastography in determining malignancy potential and calculating objective BIRADS US scores using ultrasonography and elastography features. Pol J Radiol 2018;83:e268-74

24. Bojanic K, Katavic N, Smolic M, Peric M, Kralik K, Sikora M, et al. Implementation of elastography score and strain ratio in combination with B-mode ultrasound avoids unnecessary biopsies of breast lesions. Ultrasound Med Biol 2017;43:804-16.

25. Parajuly SS, Lan PY, Yun MB, Gang YZ, Hua Z. Diagnostic potential of strain ratio measurement and a 5-point scoring method for detection of breast cancer: Chinese experience. Asian Pac J Cancer Prev. 2012;13(4):1447-52

26. Gheonea IA, Stoica Z, Bondari S. Differential diagnosis of breast lesions using ultrasound elastography. Indian J Radiol Imaging 2011;21:301-5.

27. Li L, Zhou X, Zhao X, Hao S, Yao J, Zhong W, et al. B-mode ultrasound combined with color Doppler and strain elastography in the diagnosis of non-mass breast lesions: A prospective study. Ultrasound Med Biol 2017;43:2582-90.

28. Barr RG, Zhang Z, Cormack JB, Mendelson EB, Berg WA. Probably benign lesions at screening breast US in a population with elevated risk: Prevalence and rate of malignancy in the ACRIN 6666 trial. Radiology 2013;269:701-12.

29. Alhabshi SM, Rahmat K, Abdul Halim N, Aziz S, Radhika S, Gan GC, et al. Semi-quantitative and qualitative assessment of breast ultrasound elastography in differentiating between malignant and benign lesions. Ultrasound Med Biol 2013;39:568-78.

30. Menezes R, Sardessai S, Furtado R, Sardessai M. Correlation of strain elastography with conventional sonography and FNAC/biopsy. J Clin Diagn Res 2016;10:5-10.

31. Arslan S, Öncü F, Eryılmaz MA, Durmaz MS, Altunkeser A, Ünlü Y. Advantages of b-mode ultrasound combined with strain elastography in differentiation of idiopathic granulomatous mastitis from malignant breast lesions. Turk J Med Sci 2018;48:16-23

32. Chen YL, Chen JJ, Chang C, Gao Y, Wu J, Yang WT, et al. Sclerosing adenosis: Ultrasonographic and mammographic findings and correlation with histopathology. Mol Clin Oncol 2017;6:157-62.

33. Li LJ, Zeng H, Ou B, Luo BM, Xiao XY, Zhong WJ, et al. Ultrasonic elastography features of phyllodes tumors of the breast: A clinical research. PLoS One 2014;9:e85257.

34. Khanduri S, Khan M, Shukla A, Khan S, Ali I, Ahmad ZS, et al. Characterization of breast lesions using a novel combined approach of ultrasonography and elastography prior to invasive procedures: Are new age modalities set to replace the diagnostic giant? Cureus 2019;11:e4954.

35. Huang M, Jiang T, Zhao Q, You Q, Tian G, Wang B. Breast adenoid 
cystic carcinoma: Report of a case with emphasis on routine sonographic findings and shear wave elastography. J Med Ultrason $20012018 ; 45: 181-4$.

36. Ichikawa K, Mizukami Y, Takayama T, Takemura A, Miyati T, Taniya T. A case of adenoid cystic carcinoma of the breast. J Med Ultrason 2001 2007;34:193-6.

37. Tang W, Peng WJ, Gu YJ, Zhu H, Jiang TT, Li C. Imaging manifestation of adenoid cystic carcinoma of the breast. J Comput Assist Tomogr 2015;39:523-30.

38. Jin FL, Du J, Guo Y. Strain elastography features in invasive breast cancer: Relationship between stiffness and pathological factors. Int J Clin Exp Med 2017;10:13290-7.
39. Meyer JE, Amin E, Lindfors KK, Lipman JC, Stomper PC, Genest D. Medullary carcinoma of the breast: Mammographic and US appearance. Radiology 1989;170:79-82.

40. Choi JJ, Kang BJ, Kim SH, Lee JH, Jeong SH, Yim HW, et al. Role of sonographic elastography in the differential diagnosis of axillary lymph nodes in breast cancer. J Ultrasound Med 2011;30:429-36.

41. Mu WJ, Zhong WJ, Yao JY, Li LJ, Peng YL, Wang Y, et al. Ultrasonic elastography research based on a multicenter study: Adding strain ratio after 5-point scoring evaluation or not. PloS one 2016;11:e0148330.

42. Yerli H, Yilmaz T, Kaskati T, Gulay H. Qualitative and semiquantitative evaluations of solid breast lesions by sonoelastography. J Ultrasound Med 2011;30:179-86. 